\title{
Non-alcoholic Fatty Liver Disease in Lean Subjects: Characteristics and Implications
}

\author{
Ramesh Kumar* and Shantam Mohan \\ Department of Medical Gastroenterology, Paras HMR Institute, Patna, India
}

\begin{abstract}
Non-alcoholic fatty liver disease (NAFLD) is commonly diagnosed in obese subjects; however, it is not rare among lean individuals. Given the absence of traditional risk factors, it tends to remain under-recognised. The metabolic profiles of lean NAFLD patients are frequently comparable to those of obese NAFLD patients. Though results from several studies have been mixed, it has been generally revealed that lean subjects with NAFLD have minor insulin resistance compared to that in obese NAFLD. Several genetic variants are associated with NAFLD without insulin resistance. Some data suggest that the prevalence of steatohepatitis and advanced fibrosis do not differ significantly between lean and obese NAFLD; however, the former tend to have less severe disease at presentation. The underlying pathophysiology of lean NAFLD may be quite different. Genetic predispositions, fructose- and cholesterol-rich diet, visceral adiposity and dyslipidaemia have potential roles in the pathogenic underpinnings. Lean NAFLD may pose a risk for metabolic disturbances, cardiovascular morbidity or overall mortality. Secondary causes of hepatic steatosis are also needed to be ruled out in lean subjects with NAFLD. The effectiveness of various treatment modalities, such as exercise and pharmacotherapy, on lean NAFLD is not known. Weight loss is expected to help lean NAFLD patients who have visceral obesity. Further investigation is needed for many aspects of lean NAFLD, including mechanistic pathogenesis, risk assessment, natural history and therapeutic approach.
\end{abstract}

Citation of this article: Kumar R, Mohan S. Non-alcoholic fatty liver disease in lean subjects: characteristics and implications. J Clin Transl Hepatol 2017;5(3):216-223. doi: 10.14218/JCTH.2016.00068.

Keywords: Lean; NAFLD; BMI; Non-obese.

Abbreviations: BMI, body mass index; CETP, cholesteryl ester transfer protein; DM, diabetes mellitus; HOMA-IR, homeostasis model assessment insulin resistance; IR, insulin resistance; LDL, low-density lipoprotein; LXRa, liver X receptor a; MS, metabolic syndrome; NAFLD, non-alcoholic fatty liver disease; NASH, nonalcoholic steatohepatitis; NHANES, National Health and Nutrition Examination Survey; PNPLA, palatin-like phospholipase domain-containing; SIBO, small intestinal bacterial overgrowth; SNP, single nucleotide polymorphism; SREBP, stero regulatory element binding protein; VLDL, very low density lipoproteins; WC, waist circumference.

Received: 23 November 2016; Revised: 7 March 2017; Accepted: 15 May 2017

* Correspondence to: Dr Ramesh Kumar, Department of Gastroenterology, Institute of Gastrosciences, Medical Divisions, Paras HMR Institute, Patna 800014, India. Tel: +612-7107700-7852, E-mail: docrameshkr@gmail.com

\section{Introduction}

Non-alcoholic fatty liver disease (NAFLD) is a major cause of chronic liver disease worldwide. ${ }^{1,2}$ The spectrum of NAFLD ranges from simple steatosis and non-alcoholic steatohepatitis (NASH) to cirrhosis. Obesity is considered a key player in the development of NAFLD, and the majority of patients with NAFLD are either obese or overweight. However, NAFLD has been reported in lean subjects residing in developing countries as well as developed countries. ${ }^{3-9}$ Lean NAFLD may represent a distinct entity, rather than merely a by-product of different body mass index (BMI). Moreover, NAFLD in the lean subjects suggests a phenotypic distinctiveness that raises the possibility of a different pathophysiology.

There is no standard definition of lean NAFLD, and BMI cut-off points for overweight and obesity are not uniform across the world. Studies have shown that for a given BMI, Asians generally have a higher proportion of body fat than do Europeans. ${ }^{10}$ Asian populations have also been shown to have an elevated risk of type 2 diabetes mellitus (DM), hyperlipidaemia and hypertension at a relatively low level of BMI. Therefore, the recommended BMI cut-off points for Asians for defining overweight $\left(23-25 \mathrm{~kg} / \mathrm{m}^{2}\right)$ and obesity $\left(>25 \mathrm{~kg} / \mathrm{m}^{2}\right)$ are lesser than those of Western populations. ${ }^{10}$ The term "lean NAFLD" is used to describe fatty liver in patients who are not overweight or obese, as per region-specific BMI. Therefore, NAFLD with BMI $<23 \mathrm{~kg} / \mathrm{m}^{2}$ for Asian populations and $<25 \mathrm{~kg} / \mathrm{m}^{2}$ for non-Asian populations are considered lean NAFLD. The respective BMI cut-off points for non-obese NAFLD are $<25 \mathrm{~kg} / \mathrm{m}^{2}$ and $30 \mathrm{~kg} / \mathrm{m}^{2}$, respectively.

\section{Epidemiology}

The study population and diagnostic modalities used in the diagnosis of NAFLD impact the assessment of NAFLD epidemiology. ${ }^{1}$ Several diagnostic modalities have been used for the diagnosis of fatty liver, including ultrasound, liver enzymes, computed tomography, magnetic resonance imaging spectroscopy (MRS) and liver biopsy. Among these, ultrasound is perhaps the most practical way to assess hepatic steatosis, due to its relatively low cost, fair accuracy and non-invasive nature. Liver enzymes may be within normal range in a significant proportion of NAFLD patients; therefore, those levels cannot be used to exclude the presence of NAFLD reliably.

Liver biopsy is the gold standard; however, it is not feasible or ethical to perform liver biopsies in all suspected cases. MRS is highly accurate for even minimal amounts of steatosis; however, its cost limits its use in routine clinical practice. Most population studies have used ultrasound scan for the 
diagnosis of fatty liver (Table 1). Even ultrasound, though, is far from being accurate; it is operator-dependent, and has limited sensitivity and specificity for the diagnosis of fatty liver. A meta-analysis of 46 studies $^{11}$ revealed that application of ultrasound for the evaluation of hepatic steatosis had sensitivity of $73.3 \%$ and specificity of $69.6 \%$, when compared to histopathology as the reference standard.

The reported prevalence rates of NAFLD among lean and non-obese subjects in the literature are summarized in Table 1. In a recent study from the Unites States, population prevalence of NAFLD was estimated using data from the National Health and Nutrition Examination Survey III (NHANES III) database. ${ }^{12}$ Among the 11,613 eligible participants, $18.8 \%$ had NAFLD and $3.7 \%$ had lean NAFLD. The overall prevalence of NAFLD among lean subjects was $9.67 \%$ (431/4457), whereas it was $28.8 \%(2061 / 7156)$ in the non-lean subjects. ${ }^{12}$ This was the largest study published so far on the prevalence of lean NAFLD using a nationwide sample. Also, the lean NAFLD patients were less likely to have components of metabolic syndrome (MS).

In a prospective community-based epidemiological study from rural India, overall prevalence of NAFLD was $8.7 \%$ $(164 / 1911){ }^{3}$ while the prevalence among lean individuals (BMI $<23 \mathrm{~kg} / \mathrm{m}^{2}$ ) was $5.1 \%$. Among NAFLD subjects, $75 \%$ had a BMI lower than $25 \mathrm{~kg} / \mathrm{m}^{2}$ and $54 \%$ were not even overweight. However, extrapolating this data to other populations would be difficult because the entire screened population had unusually low BMI. Overall, $87 \%$ of the participants were lean and only $7 \%$ had BMI $>25 \mathrm{~kg} / \mathrm{m}^{2}$.

Data from the Dionysos study in northern Italy, which utilized ultrasonography to determine steatosis in 257 subjects, showed that the prevalence of NAFLD in the lean, non-drinking population was $16.4 \%$, while in the obese population the prevalence was $75.8 \%{ }^{13}$ In a study from Korea $(n=29994)$, the prevalence of NAFLD was $12.6 \%$ in non-obese (BMI $<25 \mathrm{~kg} / \mathrm{m}^{2}$ ) subjects and $50.1 \%$ in obese subjects. ${ }^{14}$ This is the largest community-based study from the East. In another Korean study, where data of 5,878 nonobese (BMI $<25 \mathrm{~kg} / \mathrm{m}^{2}$ ), non-diabetic individuals were analysed, the prevalence of NAFLD was $27 \%$. When only lean subjects were considered (BMI $<23 \mathrm{~kg} / \mathrm{m}^{2}$ ), the prevalence of NAFLD was still considerably high, at $16 \% .{ }^{15}$ In a study from China, the prevalence of NAFLD was $7.27 \%$ in 6,905 non-obese subjects; among these, 5,562 subjects who were free of NAFLD at baseline completed the 5-year follow-up study, with 494 (8.8\%) having developed NAFLD. ${ }^{16}$ In that study, an increase in BMI and waist circumference (WC) was found to be independently associated with development of NAFLD during follow-up.

It is difficult to establish the prevalence of NASH in the general population because of the need of liver histology. Non-invasive methods cannot accurately determine the histological severity and prognosis of liver damage. Most studies have diagnosed NASH on the basis of criteria such as elevated liver enzymes, presence of DM or insulin resistance (IR). In the NHANES III study, ${ }^{12}$ NAFLD patients with elevated liver enzymes in presence of DM or IR were presumed to have $\mathrm{NASH}$, and the prevalence of presumed NASH in non-obese subjects was $0.1 \%$. In an autopsy series of 351 apparently non-alcoholic patients, Wanless et al. ${ }^{17}$ found that $18.5 \%$ of markedly obese subjects and $2.7 \%$ of lean subjects had steatohepatitis.

A major limitation of most of the ultrasound-based studies remains the poor accuracy of the ultrasound when hepatic steatosis is $<30 \%$, for which ultrasound tends to underestimate the true prevalence of NAFLD. Mild steatosis may constitute an important proportion among the patients with lean NAFLD. That is why a higher (19.3\%) prevalence rate of NAFLD was found in a study from HongKong when MRS was used as diagnostic modality. ${ }^{18}$ Thus, it is increasingly clear that NAFLD is not so rare in lean subjects. The variations in the prevalence rates suggest that further studies, using consistent and accurate diagnostic modalities, are needed to provide true prevalence of lean NAFLD worldwide. Also, attempts should be made to provide estimates of the global prevalence of lean NASH using liver histology.

\section{Clinical and metabolic characteristics}

Lean NAFLD patients are often asymptomatic; and, compared to obese NAFLD patients, they have lower body weight and WC. This is why many of such patients fail to seek medical advice. However, compared to lean healthy controls, lean NAFLD patients have higher BMI, blood pressure, fasting blood sugar, and higher prevalence of dyslipidaemia and MS. ${ }^{5}$ The demographic and metabolic characteristics of lean and non-obese NAFLD patients have been summarised in Table 2.

Table 1. Prevalence of NAFLD among lean and non-obese subjects

\begin{tabular}{|c|c|c|c|c|c|}
\hline \multirow[b]{2}{*}{ Study ${ }^{\text {Ref }}$} & \multirow[b]{2}{*}{ Country } & \multirow[b]{2}{*}{$n$} & \multirow[b]{2}{*}{ Mode of diagnosis } & \multicolumn{2}{|l|}{ Prevalence } \\
\hline & & & & Non-obese/Lean & Obese/Overweight \\
\hline Younossi et al. ${ }^{12}$ & United States & 11,613 & USG & $9.6 \%$ & $28.8 \%$ \\
\hline Xu et al. ${ }^{16}$ & China & $6,905^{*}$ & USG & $7.2 \%$ & Not studied \\
\hline Das et $a .^{3}$ & India & 1,911 & USG/CT** & $5.1 \%$ & $31.7 \%$ \\
\hline Kwon et al. ${ }^{14}$ & Korea & 29,994 & USG & $12.6 \%$ & $50.1 \%$ \\
\hline Bellentani et al. ${ }^{13}$ & Italy & 257 & USG & $16.4 \%$ & $75.8 \%$ \\
\hline Sinn et al. ${ }^{15}$ & Korea & $5,878^{*}$ & USG & $\begin{array}{l}27 \% \text { (non-obese) } \\
16 \% \text { (lean) }\end{array}$ & Not studied \\
\hline Wei et al. ${ }^{18}$ & Hong Kong & 911 & MRS & $19.3 \%$ & $60.5 \%$ \\
\hline
\end{tabular}

* Only non-obese population.

** CT scan was used during second phase to confirm NAFLD.

Abbreviations: CT, computed tomography; MRS, magnetic resonance spectroscopy; USG, ultrasonography. 
Kumar R. et al: Lean NAFLD

Table 2. Demographic and metabolic profiles of lean NAFLD patients in different studies

\begin{tabular}{|c|c|c|c|c|c|c|c|c|c|c|}
\hline Study, ${ }^{\text {Ref }}$ Country & $n$ & $\begin{array}{l}\text { Age* }^{*} \\
\text { (years) }\end{array}$ & $\begin{array}{l}\text { Male: } \\
\text { Female }\end{array}$ & $\begin{array}{l}\text { BMI* }^{*} \\
\left(\mathrm{~kg} / \mathrm{m}^{2}\right)\end{array}$ & $\begin{array}{l}\text { WC* } \\
(\mathrm{cm})\end{array}$ & $\begin{array}{l}\text { DM } \\
(\%)\end{array}$ & $\begin{array}{l}\text { HOMA- } \\
\text { IR* }^{*}\end{array}$ & $\begin{array}{l}\text { HTN } \\
(\%)\end{array}$ & $\begin{array}{l}\text { AST/ALT* } \\
(\mathrm{IU} / \mathrm{L})\end{array}$ & $\begin{array}{l}\text { Serum } \\
\text { Chol/TG/HDL* } \\
(\mathrm{mg} / \mathrm{dL})\end{array}$ \\
\hline $\begin{array}{l}\text { Younossi et al., }{ }^{12} \\
\text { USA }\end{array}$ & 431 & 42 & $187: 244$ & 22.1 & NA & 6.7 & 2.7 & 17.8 & $21 / 17$ & NA \\
\hline $\begin{array}{l}\text { Honda et al., } \\
\text { Japan }\end{array}$ & 134 & 56 & $57: 77$ & 22.8 & NA & 32 & 3.4 & NA & $47 / 70$ & $213 / 144 / 57$ \\
\hline $\begin{array}{l}\text { Feng et al.. }{ }^{9} \\
\text { China }\end{array}$ & 134 & 48 & $72: 62$ & 22.7 & 82 & 15 & 2.1 & 34 & $21 / 21$ & $5.2 / 1.7 / 1.4^{\#}$ \\
\hline $\begin{array}{l}\text { Alam et al., } \\
\text { Bangladesh }\end{array}$ & 119 & 41 & $62: 57$ & 23.0 & 87 & 26 & 1.9 & 21 & $43 / 52$ & $202 / 243 / 36$ \\
\hline $\begin{array}{l}\text { Kumar et al., } \\
\text { India }\end{array}$ & 27 & 38 & $19: 08$ & 21.7 & 80 & 3.7 & 1.7 & 15 & $38 / 45$ & $203 / 190 / 40$ \\
\hline $\begin{array}{l}\text { Leung et al., }{ }^{4} \\
\text { Hong Kong }\end{array}$ & 29 & 56 & $13: 16$ & 22.1 & 79 & 52 & NA & 41 & $25 / 45$ & $3.7 / 1.4 / 1.5^{*}$ \\
\hline $\begin{array}{l}\text { Kim et al.., } \\
\text { Korea }\end{array}$ & 74 & 51 & $48: 26$ & 23.4 & 83 & 10 & 2.6 & 43 & $23 / 31$ & $208 / 194 / 44$ \\
\hline $\begin{array}{l}\text { Bhat et al.. } \\
\text { India }\end{array}$ & 30 & 39 & NA & 21.7 & 84 & NA & 3.5 & NA & NA/69 & $177 / 185 / 38$ \\
\hline $\begin{array}{l}\text { Akyuz et al., } \\
\text { Turkey }\end{array}$ & 37 & 41 & $26: 11$ & 23.6 & NA & 27 & 2.8 & NA & $49 / 82$ & $211 / 167 / 47$ \\
\hline $\begin{array}{l}\text { Margariti et al., } \\
\text { Greece }\end{array}$ & 19 & 19 & $11: 08$ & $<25$ & 94 & 5 & NA & 16 & $45 / 92$ & $223 / 145 / 51$ \\
\hline
\end{tabular}

* Data expressed in mean or median. NA: Data not available.

\#Data in $\mathrm{mmol} / \mathrm{L}$.

Abbreviations: ALT, alanine aminotransferase; AST, aspartate aminotransferase; BMI, body mass index; Chol, total cholesterol; DM, diabetes mellitus; HDL, high density lipoprotein; HOMA-IR, homeostasis model assessment insulin resistance; HTN, hypertension; TG, triglyceride; WC, waist circumference.

The metabolic characteristics of lean NAFLD subjects vary across ethnicities. A study revealed that lean, non-alcoholic, non-diabetic, non-smoking Asian Indians-in comparison to age-, sex- and BMI-matched Caucasians, Hispanics, Blacks and Eastern Asians-had a 2- to 3-fold increase in IR and 2-fold increase in hepatic steatosis. ${ }^{19}$ Vos et al. ${ }^{20}$ reported that compared with obese NAFLD patients, lean NAFLD patients were younger, mostly male, and displayed lower fasting glucose, glycated haemoglobin and blood pressure values. Using data from NHANES III, Younossi et al. ${ }^{12}$ found that lean NAFLD was associated with younger age, female sex, and a decreased chance of having IR and hypercholesterolemia. A slight male preponderance has been found in the majority of studies on lean NAFLD, with the age ranging between 19 years and 56 years (Table 2 ).

\section{Visceral obesity}

NAFLD in lean individuals may be linked to the compartmentalization of fat at ectopic sites, such as waist and neck. Visceral obesity may play an important role in the pathogenesis of lean NAFLD. It is believed that not all excessive body fat is harmful, rather visceral obesity seems to be the metabolically hazardous one, being the main source of fatty acids and mediators of steatosis, inflammation and fibrosis. ${ }^{21,22}$ One explanation for the existence of hepatic steatosis in lean subjects could be the concept of metabolically obese, normal weight subjects. ${ }^{23}$ These normal BMI subjects develop hepatic steatosis after becoming a little heavier during adult life, with a 2 to $10 \mathrm{~kg}$ increase in weight, which was almost entirely due to an increase in body fat. ${ }^{23,24}$
WC and neck circumference are commonly used as surrogate markers of visceral adiposity. Ha et $a .^{25}$ found that visceral adiposity rendered non-obese healthy Asian subjects more susceptible to NAFLD, as compared with subcutaneous fat and BMI. Li et al. ${ }^{26}$ reported that neck circumference was an independent indicator for NAFLD in non-obese men. Considering that the body structure and fat deposition are different between males and females, we need to have anthropometric data categorized between male and female cases of lean NAFLD.

It should be noted that the WC has poor correlation with visceral obesity, as it also includes subcutaneous fat of the abdominal wall. ${ }^{27,28}$ In fact, subcutaneous fat may act a reservoir for excess lipids and might protect subjects against NAFLD by storing away extra fats. ${ }^{27}$ The recently-introduced sagittal abdominal diameter measurement, which is taken as the antero-posterior diameter of the abdomen, may have a stronger correlation with visceral adiposity, particularly among non-obese (BMI $<25 \mathrm{~kg} / \mathrm{m}^{2}$ ) subjects. ${ }^{29}$

\section{Environmental factors}

There seems to be an association between dietary habit and development of lean NAFLD. There are several well-known animal models and genetic diseases that can lead to hepatic steatosis without significant adiposity or IR. A concept related to that is the methionine and choline-deficient diet mouse model. ${ }^{30}$ Mice subjected to methionine and choline-deficient diet do not become IR or obese, but develop hepatic steatosis as a consequence of decreased beta-oxidation of fatty acids, 
a decrease in very low density lipoproteins (VLDLs), and a reduction in triglyceride export from hepatocytes. ${ }^{31}$

Fructose ingestion may play an important role in development of NAFLD in lean subjects. A study found soft drink consumption to be significantly associated with hepatic steatosis, independent of metabolic risk factors. ${ }^{32}$ Nonobese NAFLD subjects have been found to consume higher amounts of added sugar, such as soft drinks and juices, compared to healthy controls. ${ }^{33}$ Furthermore, consumption of high cholesterol diet may lead to NAFLD in lean subjects, even when the total caloric intake may not be excessive.

A study found that cholesterol intake was significantly higher in non-obese NAFLD patients than their obese NAFLD counterparts. ${ }^{34}$ In an Italian study, consumption of higher cholesterol was noted in NASH patients with normal BMI compared to the BMI-matched controls. ${ }^{35}$ The metabolites of cholesterol, such as oxysterols, serve as endogenous ligands for the liver $X$ receptor a ( $L X R a)$, which also mediates sterol regulatory element binding protein 1c (SREBP1c) activation, ultimately increasing de novo lipogenesis and hepatic steatosis. ${ }^{36}$ Increased expression of LXRa has been found in patients with non-obese NAFLD, as compared with obese ones. ${ }^{37,38}$ Cholesterol may promote apoptosis of hepatocytes and macrophages, formation of reactive oxygen species, and lipid peroxidation. ${ }^{39,40}$

\section{Genetic predisposition}

Several genetic variants have been associated with NAFLD, with or without IR or other metabolic risk factors. Considering inter-ethnic variations in susceptibility, genetic factors may be important in the lean subjects with NAFLD.

\section{Palatin-like phospholipase domain-containing 3 (PNPLA3)}

PNPLA3 is a widely studied gene encoding for adiponutrin. The Dallas Heart Study found a strong association between hepatic steatosis and a variant allele (rs738409) of PNPLA3. ${ }^{41}$ Asian populations were also shown to have a higher prevalence of the PNPLA3 148M polymorphism associated with steatosis, as compared with that observed in Europeans and Africans. ${ }^{42}$ A population-based study from Hong Kong revealed that a higher proportion of patients with non-obese NAFLD than those with obese NAFLD carried the variant PNPLA3 allele (78.4\% vs. $59.8 \%$ ), and the PNPLA3 polymorphism remained an independent risk factor for non-obese NAFLD after adjusting for other metabolic risk factors. ${ }^{18}$

PNPLA3 rs738409 may affect the pathogenesis of NAFLD in non-obese individuals compared with obese individuals, and may have an additive joint effect along with such changes in lifestyle as weight gain $>10 \mathrm{~kg}$ after age $20 .{ }^{43}$ Notably, the PNPLA3 variant is associated not only with hepatic steatosis but also with more aggressive forms of NAFLD, such as NASH, fibrosis and liver cancer. ${ }^{44,45}$ The mechanism by which the PNPLA3 polymorphism may cause NAFLD remains poorly understood. However, data suggest that it is not mediated through IR, obesity or dyslipidemia. ${ }^{46,47}$ Some plausible mechanisms could be impairment of hepatocellular lipolysis, remodelling of lipid droplets, and interference with VLDL secretion and retinol metabolism via retinyl-palmitate lipase activity. ${ }^{48-50}$

\section{Cholesteryl ester transfer protein (CETP)}

CETP plays an important role in transport of cholesterol from peripheral tissue back to the liver. Two single nucleotide polymorphisms (SNPs) on the CETP gene, namely rs 12447924 and rs12597002, have been found to be associated with an increased risk of hepatic steatosis, particularly in non-obese subjects. ${ }^{51}$

\section{Sterol regulatory element binding protein (SREBP)}

The SREBP gene codes the SREBP-2 transcription factor that regulates genes involved in the biosynthesis, uptake and excretion of cholesterol. ${ }^{52}$ A recent study found that SREBP-2 polymorphism (rs133291) was associated with development of NAFLD in non-obese subjects without other metabolic risk factors. ${ }^{53}$ Furthermore, SREBP-2 was associated with severity of NAFLD and with higher odds of NASH (odds ratio: 2.9) among patients with non-obese NAFLD. ${ }^{53}$

\section{Apolipoprotein 3 (APOC3)}

Lean Indian men with NAFLD were found to carry two gain-offunction SNPs within the gene encoding APOC3. ${ }^{54}$ The variant allele carriers had a $30 \%$ increase in plasma APOC 3 and a $60 \%$ increase in plasma triglycerides, as well as marked IR.

\section{IR}

IR is an important trigger for initiation of NAFLD. NAFLD has been shown to be associated with IR independently of BMI, ${ }^{55}$ and studies have reported that IR is present in a significant proportion of lean NAFLD patients even without other metabolic risk factors. ${ }^{7,56}$ A study revealed that lean, non-alcoholic Asian Indians had 2- to 3-fold increase in IR in comparison to matched Caucasians, Hispanics, Blacks and Eastern Asians. ${ }^{19}$ However, IR is not universally present in all lean NAFLD patients. Several studies have revealed that lean NAFLD patients have little or no IR. ${ }^{5,12}$

Various genetic factors are known to confer susceptibility to NAFLD in individuals without IR. ${ }^{46,47,57}$ Patients with mutations in adipose triglyceride lipase and comparative gene identification-58 have been found to have severe steatosis but no IR. ${ }^{58} \mathrm{~A}$ genetic variant in PNPLA3 has been shown to be associated with hepatic steatosis without IR. ${ }^{57} \mathrm{~A}$ recent study on the effect of vitamin E in patients with NAFLD has found a significant improvement in hepatic histology without any change in IR. ${ }^{59}$

The discrepancies in the reports of presence or absence of IR in lean NAFLD can be partly explained by the facts that IR measured by the homeostasis model assessmentinsulin resistance (HOMA-IR) index reflects only hepatic IR, while peripheral IR may be still present in such patients. IR at adipose tissue may trigger excess release of fatty acids, leading to development of hepatic lipotoxicity in NAFLD. However, convincing data to suggest that peripheral IR plays an important role in the pathogenesis of lean NAFLD is lacking. A study has reported that patients with NASH have severe adipose tissue IR independent of the degree of obesity. ${ }^{60}$ In a recent study, Feldman et al. ${ }^{61}$ have found that lean subjects with NAFLD are insulin resistant and have evidence of dysfunctional adipose tissues. Additional works are needed to gain a better understanding of this association. 


\section{Dyslipidaemia}

Several studies have revealed a frequent occurrence of dyslipidaemia in lean NAFLD patients. ${ }^{5,6,12,62}$ The liver plays an important role in lipid metabolism and may be involved in the development of dyslipidaemia in NAFLD. ${ }^{62}$ Impaired hepatic lipid handling may occur in patients with NAFLD, causing faulty lipid homeostasis and initiation of dyslipidaemia. Individuals with dyslipidaemia without obesity are termed as normal weight dyslipidaemia. The estimates of prevalence of normal weight dyslipidaemia in the general population range from $10 \%$ to $37 \%$. $^{63}$

Several new studies suggest an important role of intrahepatic fat in the development of dyslipidaemia and IR in humans. ${ }^{64,65}$ In cases with IR, hepatic fat deposition is further propagated, as the resulting hyperinsulinemia and hyperglycaemia activate SREBP and carbohydrate-SREBP, respectively. These transcription factors up-regulate de novo lipogenesis and, subsequently, hepatic lipid accumulation. ${ }^{66}$ Furthermore, cholesterol metabolites such as oxysterols mediate SREBP1c activation, ultimately enhancing lipogenesis and hepatic steatosis. ${ }^{36}$

A study by Kim et al. ${ }^{67}$ demonstrated that triglyceride levels were significantly associated with both the development and regression of NAFLD among non-obese Koreans. Oxidized low-density lipoprotein (LDL) is a powerful immunogenic molecule, which causes oxidative stress and produces antibodies (i.e. oxLDL-ab). A study has revealed that oxLDL$\mathrm{ab} / \mathrm{HDL}$ ratio is associated with severity of hepatocellular ballooning and liver fibrosis in lean NAFLD patients. This ratio could play an important role in distinguishing mild from severe states of NAFLD. ${ }^{68}$

\section{Cytokines and adipokines}

Cytokines play important roles in the pathogenesis of NAFLD. The macrophages residing in the adipose tissue remain important source of cytokines. ${ }^{69,70}$ Cytokine profile alteration in NAFLD patients has been associated with degree of adiposity. However, it appears that alterations in the levels of cytokines (TNF $\alpha$, IL- 1 and IL- 6 ) and adipokines (leptin and adiponectin) are not significantly different between lean and obese NAFLD subjects. ${ }^{5,71}$

The adipose tissues of lean NAFLD patients may have more pro-inflammatory potential. In fact, cytokine secretion has been related to adipocyte location and size. Visceral adipocytes tend to be smaller than subcutaneous adipocytes but, nonetheless, have greater potential to secrete cytokines. ${ }^{21,72}$ The visceral adiposities have been documented in lean
NAFLD patients. Another trigger for cytokine production in NAFLD could be small intestinal bacterial overgrowth (SIBO) and the resulting endotoxemia. ${ }^{73}$ In several studies, SIBO and endotoxin from gut-derived bacteria have been shown as associated with NAFLD. ${ }^{73-75}$ However, similar data pertaining to lean NAFLD is not yet available.

\section{Secondary causes of hepatic steatosis}

NAFLD is commonly associated with DM, obesity, dyslipidaemia and IR; however, other less common specific conditions can cause hepatic steatosis. These are hypobetalipoproteinaemia, celiac disease, cystic fibrosis, lipodystrophy, hepatitis $C$ virus infection, severe surgical weight loss, Wilson's disease, total parental nutrition and inflammatory bowel disease. ${ }^{76-78}$ Several drugs, such as amiodarone, tamoxifen, methotrexate and corticosteroids, have been implicated in the causation of fatty liver. ${ }^{78}$ While evaluating a lean patient with NAFLD, these causes must be taken into account, as they may require a different approach in the diagnosis and treatment.

\section{Pathological characteristics}

The underlying pathophysiologic basis of NAFLD in lean subjects remains uncertain, with conflicting data. It appears that there is no single pathway to this multifactorial phenotype. Genetic predisposition acting together with environmental influences, such as dietary composition and gut microbiome may have an important role. Polymorphisms in genes affecting lipid metabolism, oxidative stress, IR and immune regulation have been identified as predisposing factors for the development of NAFLD. The peripheral IR might contribute to steatosis by increasing lipolysis and delivery of free fatty acids to the liver. It is likely that multiple hits, acting together on genetically predisposed lean subjects induce NAFLD.

The published series that have included liver biopsy of non-obese NAFLD cases have yielded conflicting and inconclusive results. In general, patients with lean NAFLD tend to have less severe disease compared to obese patients (Table 3). Kumar et al. ${ }^{5}$ reported that the mean NAFLD activity score in lean NAFLD patients was significantly lower than that in obese NAFLD patients $(3.3 \pm 1.5 \mathrm{vs} .4 .1 \pm 1.4$, $p<0.001)$. However, $28 \%$ of the lean NAFLD patients met the criteria for NASH, which was statistically similar to the prevalence of NASH in the obese NAFLD (38\%) patients. The proportion of patients with hepatic fibrosis was significantly lower in the lean NAFLD patients compared to the obese NAFLD patients $(50 \%$ vs. $84 \%, p<0.01)$.

Table 3. Histological severity of lean NAFLD compared to obese NAFLD

\begin{tabular}{|c|c|c|c|c|c|c|c|c|c|}
\hline \multirow[b]{2}{*}{ Study ${ }^{\text {Ref }}$} & \multirow{2}{*}{$\begin{array}{l}\text { Lean/ } \\
\text { Obese }\end{array}$} & \multicolumn{2}{|l|}{ NAS $(0-8)$} & \multicolumn{2}{|l|}{ Fibrosis } & \multicolumn{2}{|c|}{ NASH NAS > 4} & \multicolumn{2}{|c|}{ Advanced Fibrosis $>$ F2 } \\
\hline & & Lean & Obese & Lean & Obese & Lean & Obese & Lean & Obese \\
\hline Leung et al. ${ }^{4}$ & $72 / 235$ & $3.3 \pm 1.3$ & $3.8 \pm 1.2^{*}$ & $1.3 \pm 1.5$ & $1.7 \pm 1.4^{*}$ & $43.5 \%$ & $51.9 \%$ & $26.1 \%$ & $27.7 \%$ \\
\hline Alam et al. ${ }^{6}$ & $56 / 164$ & $4.4 \pm 1.4$ & $4.1 \pm 1.1$ & $1.2 \pm .8$ & $1.1 \pm 0.8$ & $53.5 \%$ & $46.9 \%$ & $19.6 \%$ & $18.9 \%$ \\
\hline Kumar et al. ${ }^{5}$ & $18 / 73$ & $3.3 \pm 1.5$ & $4.1 \pm 1.4$ & $01(0-04)$ & $02(0-04)^{*}$ & $28 \%$ & $38 \%$ & $5.6 \%$ & $27 \%$ \\
\hline Akyuz et al. ${ }^{79}$ & $37 / 446$ & $5(2-7)$ & $5(4-6)$ & $0(0-1)$ & $1(0-2)^{*}$ & - & - & 0 & 0 \\
\hline Honda et al. ${ }^{8}$ & $134 / 406$ & $3.5 \pm 1.6$ & $4.2 \pm 1.5^{*}$ & $1.6 \pm 1.1$ & $1.7 \pm 1.0$ & - & - & & - \\
\hline
\end{tabular}

* Significantly different between lean and obese.

Abbreviations: NAS, NAFLD activity score; NASH, non-alcoholic steatohepatitis. 
In a recent large series from Hong Kong, ${ }^{4}$ histological severity and clinical outcome of 72 non-obese (BMI $<25 \mathrm{~kg} / \mathrm{m}^{2}$ ) NAFLD patients were compared with 235 obese NAFLD patients. Compared with obese patients, non-obese patients had lower NAFLD activity score $(3.3 \pm 1.3$ vs. $3.8 \pm 1.2 ; p=0.019)$ and lower fibrosis stage $(1.3 \pm 1.5$ vs. $1.7 \pm 1.4 ; p=0.004)$. Only elevated serum triglyceride level was independently associated with higher NAFLD activity score (odds ratio: 1.6 ). Other studies have also reported a lower histological severity in lean NAFLD patients compared to obese NAFLD patients. ${ }^{8,20,79}$ A study from Bangladesh found no significant difference between histology of lean and obese NAFLD cases. ${ }^{6}$ Akyuz et $a l .{ }^{79}$ reported that higher haemoglobin level predicts the histological severity and suggested that serum haemoglobin level can be used as a biomarker of severity of lean NAFLD. Notably, Yilmaz et al. ${ }^{80}$ previously demonstrated that increased haemoglobin may be a feature of NAFLD patients without MS, for whom it predicts both NASH and fibrosis.

\section{Clinical implications of lean NAFLD}

Very little information is available about natural history, prognosis and therapeutic strategies in lean subjects with NAFLD. Moreover, the evolving data have shown mixed results. It has been shown that mortality has a significant association with individuals' BMI. A large pooled analysis found a U-shaped association between BMI and the risk of death in East Asians. Overall, the risk of death among Asians, as compared with Europeans, seems to be more strongly affected by a low BMI than by a high BMI. ${ }^{81}$ Dela Cruz et al. ${ }^{82}$ followed-up 1,090 NAFLD patients, $125(11.5 \%)$ of who were lean, for 133 months (range 3-332) and found that the cumulative survival was significantly shorter in patients with lean NAFLD compared to those with non-lean NAFLD (log-rank test $=5.6 ; p<0.02$ ). This difference in survival remained significant when adjusted in a Cox regression model, with only lean NAFLD (hazard ratio: $11.8 ; 95 \%$ confidence interval: $2.8,50.1 ; p=0.001$ ) and age (hazard ratio: $1.05 ; 95 \%$ confidence interval: $1.008,1.1 ; p=$ 0.02 ) remaining significant. The patients with lean NAFLD were more commonly men, of non-Caucasian race, and had a lower prevalence of diabetes, hypertension, hypertriglyceridemia, central obesity and MS, as compared to the non-lean NAFLD patients $(p<0.004$ for all). The lean NAFLD group also had significantly lower levels of alanine aminotransferase, lower HOMA-IR, lower degree of steatosis and less advanced fibrosis, but more severe lobular inflammation than the non-lean $\operatorname{NAFLD~group~(~} p<0.03$ for all).

A recent study from Hong Kong has revealed that non-obese NAFLD $(n=72)$ patients tend to have less severe disease and may have a better prognosis than obese patients $(n=235) .{ }^{4}$ After a median follow-up of 49 months, 6 patients died, all belonging to the obese group. In a series of 1,777 patients with advanced liver disease undergoing liver biopsy, Vos et al. ${ }^{20}$ found that $2.8 \%(n=50)$ of subjects neither had obesity nor diabetes, and this was the most common cause of cryptogenic liver disease. Compared with obese patients with NAFLD, lean NAFLD patients also showed lower degrees of hepatic inflammation and fibrosis. ${ }^{20} \mathrm{~A}$ study from China described that NAFLD without obesity adds significant risk for DM and MS. ${ }^{9}$

There remains a lack of data describing the association between lean NAFLD and cardiovascular disease. Although, Sung et al. ${ }^{83}$ has described that the severity of NAFLD is associated with increased cardiovascular risk in a large cohort of non-obese Asian subjects.

\section{Therapeutic implications}

To date, there is no approved pharmacological therapy for NAFLD. Most clinical attempts have been directed at treating the individual components of MS. Therefore, lifestyle changes targeted at weight loss, dietary modifications and exercise remain the first-line therapy. There is no reliable data to suggest effectiveness of lifestyle modifications in lean patients with NAFLD.

We believe that weight loss can be particularly helpful in a subset of lean NAFLD patients who have visceral obesity. Jin et al. ${ }^{84}$ evaluated the efficacy of dietary modification and exercise on the degree of steatosis, in a study of 1,365 persons with non-obese NAFLD. After lifestyle modification, they found an $86 \%$ improvement in the degree of steatosis at the time of follow-up biopsy. On multivariate analysis, weight reduction of $\geq 5 \%$, higher baseline steatosis, and total cholesterol reduction of $\geq 10 \%$, were significantly associated with steatosis improvement in non-obese patients with NAFLD. Kim et al., ${ }^{67}$ in a longitudinal study, found that reduction of body weight was significantly associated with regression of NAFLD in non-obese NAFLD.

Restriction of food and beverages high in fructose or cholesterol may be beneficial in lean NAFLD patients. Dyslipidaemia, which is frequently seen in patients with lean NAFLD, should be treated. An initial attempt should be also made to rule out secondary causes of fatty liver, such as drugs, hypobetalipoproteinaemia, familial hypercholesterolemia, lipodystrophy, celiac disease, etc. Trials exploring the potential effects of anti-oxidants, insulin sensitizers, cytoprotective agents or other modalities on lean NAFLD are eagerly awaited. One of the key areas for future research direction could be the identification of the linkage between significant genes and metabolic pathways involved in the development of lean NAFLD. These biological indicators can be used for novel drug development in the future.

In conclusion, lean NAFLD is now frequently recognised in day-to-day clinical practice; however, the data on epidemiology, risk factors, physiopathology, distinctive histologic changes, natural history and treatment of this entity are still scant. There are limitations in the estimations of precise prevalence of lean NAFLD due to absence of clinical manifestations and poor accuracy of ultrasound for mild steatosis. Researchers have used different BMI cut-offs to define lean NAFLD, which introduce difficulty in interpreting the results of studies and in making meaningful comparisons between studies. From a biological point of view, lean NAFLD behaves much like obese NAFLD; however, the absence of significant adiposity suggests a phenotypic distinctiveness. Compared to obese NAFLD subjects, lean NAFLD subjects appear to have less severe disease. The underlying mechanism is not well known but may hint at genetic and environmental risk factors that may not be present in obese NAFLD. A difficult issue with lean NAFLD patients is how to treat, given the fact that these patients already have normal weight. Therefore, additional works are needed to gain a better understanding of the disease process and implications of NAFLD in lean subjects.

\section{Conflict of interest}

The authors have no conflict of interests related to this publication. 


\section{Author contributions}

Contributed to the conception and design of the work, data acquisition, review of the literature and writing of the manuscript (RK, SM).

\section{References}

[1] Vernon G, Baranova A, Younossi ZM. Systematic review: the epidemiology and natural history of non-alcoholic fatty liver disease and non-alcoholic steatohepatitis in adults. Aliment Pharmacol Ther 2011;34:274-285. doi: 10.1111/j.1365-2036.2011.04724.x.

[2] Everhart JE, Bambha KM. Fatty liver: think globally. Hepatology 2010;51: 1491-1493. doi: 10.1002/hep.23659.

[3] Das K, Das K, Mukherjee PS, Ghosh A, Ghosh S, Mridha AR, et al. Nonobese population in a developing country has a high prevalence of nonalcoholic fatty liver and significant liver disease. Hepatology 2010;51:1593-1602. doi: $10.1002 /$ hep. 23567

[4] Leung JC, Loong TC, Wei JL, Wong GL, Chan AW, Choi PC, et al. Histological severity and clinical outcomes of nonalcoholic fatty liver disease in nonobese patients. Hepatology 2017;65:54-64. doi: 10.1002/hep.28697.

[5] Kumar R, Rastogi A, Sharma MK, Bhatia V, Garg H, Bihari C, et al. Clinicopathological characteristics and metabolic profiles of non-alcoholic fatty liver disease in Indian patients with normal body mass index: Do they differ from obese or overweight non-alcoholic fatty liver disease? Indian J Endocrinol Metab 2013;17:665-671. doi: 10.4103/2230-8210.113758.

[6] Alam S, Gupta UD, Alam M, Kabir J, Chowdhury ZR, Alam AK. Clinical, anthropometric, biochemical, and histological characteristics of nonobese nonalcoholic fatty liver disease patients of Bangladesh. Indian J Gastroenterol 2014; 33:452-457. doi: 10.1007/s12664-014-0488-5.

[7] Kim HJ, Kim HJ, Lee KE, Kim DJ, Kim SK, Ahn CW, et al. Metabolic significance of nonalcoholic fatty liver disease in nonobese, nondiabetic adults. Arch Intern Med 2004;164:2169-2175. doi: 10.1001/archinte.164.19.2169.

[8] Honda Y, Yoneda M, Kessoku T, Ogawa Y, Tomeno W, Imajo K, et al. Characteristics of non-obese non-alcoholic fatty liver disease: Effect of genetic and environmental factors. Hepatol Res 2016;46:1011-1018. doi: 10.1111/ hepr. 12648 .

[9] Feng RN, Du SS, Wang C, Li YC, Liu LY, Guo FC, et al. Lean-non-alcoholic fatty liver disease increases risk for metabolic disorders in a normal weight Chinese population. World J Gastroenterol 2014;20:17932-17940. doi: 10.3748/wjg.v20.i47.17932.

[10] WHO Expert Consultation. Appropriate body-mass index for Asian populations and its implications for policy and intervention strategies. Lancet 2004 363:157-163. doi: 10.1016/S0140-6736(03)15268-3.

[11] Bohte AE, van Werven JR, Bipat S, Stoker J. The diagnostic accuracy of US, $\mathrm{CT}, \mathrm{MRI}$ and $1 \mathrm{H}-\mathrm{MRS}$ for the evaluation of hepatic steatosis compared with liver biopsy: a meta-analysis. Eur Radiol 2011;21:87-97. doi: 10 1007/s00330-010-1905-5.

[12] Younossi ZM, Stepanova M, Negro F, Hallaji S, Younossi Y, Lam B, et al. Nonalcoholic fatty liver disease in lean individuals in the United States. Medicine (Baltimore) 2012;91:319-327. doi: 10.1097/MD.0b013e3182779d49.

[13] Bellentani S, Saccoccio G, Masutti F, Crocè LS, Brandi G, Sasso F, et al. Prevalence of and risk factors for hepatic steatosis in Northern Italy. Ann Intern Med 2000;132:112-117. doi: 10.7326/0003-4819-132-2200001180-00004.

[14] Kwon YM, Oh SW, Hwang SS, Lee C, Kwon H, Chung GE. Association of nonalcoholic fatty liver disease with components of metabolic syndrome according to body mass index in Korean adults. Am J Gastroenterol 2012;107: 1852-1858. doi: 10.1038/ajg.2012.314.

[15] Sinn DH, Gwak GY, Park HN, Kim JE, Min YW, Kim KM, et al. Ultrasonographically detected non-alcoholic fatty liver disease is an independent predictor for identifying patients with insulin resistance in non-obese, non-diabetic middle-aged Asian adults. Am J Gastroenterol 2012;107:561-567. doi: 10.1038/ajg.2011.400.

[16] Xu C, Yu C, Ma H, Xu L, Miao M, Li Y. Prevalence and risk factors for the development of nonalcoholic fatty liver disease in a nonobese Chinese population: the Zhejiang Zhenhai Study. Am J Gastroenterol 2013;108: 1299-1304. doi: 10.1038/ajg.2013.104.

[17] Wanless IR, Lentz JS. Fatty liver hepatitis (steatohepatitis) and obesity: an autopsy study with analysis of risk factors. Hepatology 1990;12:11061110. doi: 10.1002/hep.1840120505.

[18] Wei JL, Leung JC, Loong TC, Wong GL, Yeung DK, Chan RS, et al. Prevalence and severity of nonalcoholic fatty liver disease in non-obese patients: a population study using proton-magnetic resonance spectroscopy. Am J Gastroenterol 2015;110:1306-1314; quiz 1315. doi: 10.1038/ajg.2015.235.

[19] Petersen KF, Dufour S, Feng J, Befroy D, Dziura J, Dalla Man C, et al. Increased prevalence of insulin resistance and nonalcoholic fatty liver disease in Asian-Indian men. Proc Natl Acad Sci U S A 2006;103:1827318277. doi: 10.1073/pnas.0608537103.

[20] Vos B, Moreno C, Nagy N, Féry F, Cnop M, Vereerstraeten P, et al. Lean non-alcoholic fatty liver disease (Lean-NAFLD): a major cause of cryptogenic liver disease. Acta Gastroenterol Belg 2011;74:389-394.

[21] Machado MV, Cortez-Pinto $H$. No need for a large belly to have NASH. J Hepatol 2011;54:1090-1093. doi: 10.1016/j.jhep.2011.01.010.

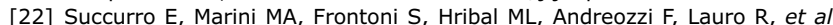
Insulin secretion in metabolically obese, but normal weight, and in metabolically healthy but obese individuals. Obesity (Silver Spring) 2008;16: 1881-1886. doi: 10.1038/oby.2008.308.

[23] Park YW, Zhu S, Palaniappan L, Heshka S, Carnethon MR, Heymsfield SB. The metabolic syndrome: prevalence and associated risk factor findings in the US population from the Third National Health and Nutrition Examination Survey, 1988-1994. Arch Intern Med 2003;163:427-436. doi: 10.1001/ archinte.163.4.427.

[24] Ruderman N, Chisholm D, Pi-Sunyer X, Schneider S. The metabolically obese, normal-weight individual revisited. Diabetes 1998;47:699-713. doi: 10.2337/diabetes.47.5.699.

[25] Ha Y, Seo N, Shim JH, Kim SY, Park JA, Han S, et al. Intimate association of visceral obesity with non-alcoholic fatty liver disease in healthy Asians: A case-control study. J Gastroenterol Hepatol 2015;30:1666-1672. doi: 10. $1111 /$ jgh. 12996

[26] Li Q, Wang N, Han B, Chen Y, Zhu C, Chen Y, et al. Neck circumference as an independent indicator to non-alcoholic fatty liver disease in non-obese men. Nutr Metab (Lond) 2015;12:63. doi: 10.1186/s12986-015-0060-z.

[27] Meng $\mathrm{K}$, Lee $\mathrm{CH}$, Saremi F. Metabolic syndrome and ectopic fat deposition: what can CT and MR provide? Acad Radiol 2010;17:1302-1312. doi: 10 1016/j.acra.2010.03.019.

[28] Bajaj S, Nigam P, Luthra A, Pandey RM, Kondal D, Bhatt SP, et al. A casecontrol study on insulin resistance, metabolic co-variates \& prediction score in non-alcoholic fatty liver disease. Indian J Med Res 2009;129:285-292.

[29] Yim JY, Kim D, Lim SH, Park MJ, Choi SH, Lee CH, et al. Sagittal abdominal diameter is a strong anthropometric measure of visceral adipose tissue in the Asian general population. Diabetes Care 2010;33:2665-2670. doi: 10. 2337/dc10-0606.

[30] Anstee QM. Animal models in nonalcoholic steatohepatitis research: utility and clinical translation. Liver Int $2011 ; 31: 440-442$. doi: $10.1111 / \mathrm{j} .1478$ 3231.2011.02463.x

[31] Hebbard L, George J. Animal models of nonalcoholic fatty liver disease. Nat Rev Gastroenterol Hepatol 2011;8:35-44. doi: 10.1038/nrgastro.2010.191.

[32] Abid A, Taha O, Nseir W, Farah R, Grosovski M, Assy N. Soft drink consump tion is associated with fatty liver disease independent of metabolic syndrome. J Hepatol 2009;51:918-924. doi: 10.1016/j.jhep.2009.05.033.

[33] Assy N, Nasser G, Kamayse I, Nseir W, Beniashvili Z, Djibre A, et al. Soft drink consumption linked with fatty liver in the absence of traditional risk factors. Can J Gastroenterol 2008;22:811-816. doi: 10.1155/2008/ 810961.

[34] Yasutake K, Nakamuta M, Shima Y, Ohyama A, Masuda K, Haruta N, et al. Nutritional investigation of non-obese patients with non-alcoholic fatty live disease: the significance of dietary cholesterol. Scand J Gastroenterol 2009; 44:471-477. doi: 10.1080/00365520802588133.

[35] Musso G, Gambino R, De Michieli F, Cassader M, Rizzetto M, Durazzo M, et al. Dietary habits and their relations to insulin resistance and postprandia lipemia in nonalcoholic steatohepatitis. Hepatology 2003;37:909-916. doi: 10.1053/jhep.2003.50132.

[36] Nakamuta M, Fujino $T$, Yada $R$, Yada $M$, Yasutake $K$, Yoshimoto $T$, et al. Impact of cholesterol metabolism and the LXRalpha-SREBP-1c pathway on nonalcoholic fatty liver disease. Int J Mol Med 2009;23:603-608.

[37] Enjoji M, Yasutake K, Kohjima M, Nakamuta M. Nutrition and nonalcoholic Fatty liver disease: the significance of cholesterol. Int J Hepatol 2012;2012: 925807. doi: $10.1155 / 2012 / 925807$.

[38] Nakamuta M, Kohjima M, Higuchi N, Kato M, Kotoh K, Yoshimoto T, et al. The significance of differences in fatty acid metabolism between obese and non-obese patients with non-alcoholic fatty liver disease. Int J Mol Med 2008;22:663-667.

[39] Yao PM, Tabas I. Free cholesterol loading of macrophages induces apoptosis involving the fas pathway. J Biol Chem 2000;275:23807-23813. doi: 10 . 1074/jbc.M002087200.

[40] Marí M, Caballero F, Colell A, Morales A, Caballeria J, Fernandez A, et al. Mitochondrial free cholesterol loading sensitizes to TNF- and Fas-mediated steatohepatitis. Cell Metab 2006;4:185-198. doi: 10.1016/j.cmet.2006. 07.006.

[41] Romeo S, Kozlitina J, Xing C, Pertsemlidis A, Cox D, Pennacchio LA, et al. Genetic variation in PNPLA3 confers susceptibility to nonalcoholic fatty liver disease. Nat Genet 2008;40:1461-1465. doi: 10.1038/ng.257.

[42] Lin YC, Chang PF, Hu FC, Yang WS, Chang MH, Ni YH. A common variant in the PNPLA3 gene is a risk factor for non-alcoholic fatty liver disease in obese Taiwanese children. J Pediatr 2011;158:740-744. doi: 10.1016/j.jpeds. 2010.11.016. 
[43] Nishioji K, Mochizuki N, Kobayashi M, Kamaguchi M, Sumida Y, Nishimura T, et al. The impact of PNPLA3 rs738409 genetic polymorphism and weight gain $\geq 10 \mathrm{~kg}$ after age 20 on non-alcoholic fatty liver disease in non-obese Japanese individuals. PLoS One 2015;10:e0140427. doi: 10.1371/journal. pone. 0140427.

[44] Sookoian S, Pirola CJ. Meta-analysis of the influence of I148M variant of patatin-like phospholipase domain containing 3 gene (PNPLA3) on the susceptibility and histological severity of nonalcoholic fatty liver disease. Hepatology 2011;53:1883-1894. doi: 10.1002/hep.24283.

[45] Singal AG, Manjunath H, Yopp AC, Beg MS, Marrero JA, Gopal P, et al. The effect of PNPLA3 on fibrosis progression and development of hepatocellular carcinoma: a meta-analysis. Am J Gastroenterol 2014;109:325-334. doi: 10.1038/ajg.2013.476.

[46] Speliotes EK, Butler JL, Palmer CD, Voight BF, GIANT Consortium, MIGen Consortium, et al. PNPLA3 variants specifically confer increased risk for histologic nonalcoholic fatty liver disease but not metabolic disease. Hepatology 2010;52:904-912. doi: 10.1002/hep.23768.

[47] Lallukka S, Sevastianova K, Perttilä J, Hakkarainen A, Orho-Melander M, Lundbom $\mathrm{N}$, et al. Adipose tissue is inflamed in NAFLD due to obesity but not in NAFLD due to genetic variation in PNPLA3. Diabetologia 2013;56: 886-892. doi: 10.1007/s00125-013-2829-9.

[48] Ruhanen H, Perttilä ], Hölttä-Vuori M, Zhou Y, Yki-Järvinen H, Ikonen E, et al. PNPLA3 mediates hepatocyte triacylglycerol remodeling. J Lipid Res 2014; 55:739-746. doi: 10.1194/jlr.M046607.

[49] Pirazzi C, Adiels M, Burza MA, Mancina RM, Levin M, Ståhlman M, et al. Patatin-like phospholipase domain-containing 3 (PNPLA3) I148M (rs738409) affects hepatic VLDL secretion in humans and in vitro. J Hepatol 2012;57: 1276-1282. doi: 10.1016/j.jhep.2012.07.030.

[50] Pirazzi C, Valenti L, Motta BM, Pingitore P, Hedfalk K, Mancina RM, et al. PNPLA3 has retinyl-palmitate lipase activity in human hepatic stellate cells. Hum Mol Genet 2014;23:4077-4085. doi: 10.1093/hmg/ddu121.

[51] Adams LA, Marsh JA, Ayonrinde OT, Olynyk JK, Ang WQ, Beilin L], et al. Cholesteryl ester transfer protein gene polymorphisms increase the risk of fatty liver in females independent of adiposity. J Gastroenterol Hepatol 2012; 27:1520-1527. doi: 10.1111/j.1440-1746.2012.07120.x.

[52] Musso G, Gambino R, Cassader M. Cholesterol metabolism and the pathogenesis of non-alcoholic steatohepatitis. Prog Lipid Res 2013;52:175-191. doi: 10.1016/j.plipres.2012.11.002.

[53] Musso G, Cassader M, Bo S, De Michieli F, Gambino R. Sterol regulatory element-binding factor 2 (SREBF-2) predicts 7-year NAFLD incidence and severity of liver disease and lipoprotein and glucose dysmetabolism. Diabetes 2013;62:1109-1120. doi: 10.2337/db12-0858.

[54] Petersen KF, Dufour S, Hariri A, Nelson-Williams C, Foo JN, Zhang XM, et al. Apolipoprotein $\mathrm{C} 3$ gene variants in nonalcoholic fatty liver disease. $N$ Engl J Med 2010;362:1082-1089. doi: 10.1056/NEJMoa0907295.

[55] Marchesini G, Brizi M, Bianchi G, Tomassetti S, Bugianesi E, Lenzi M, et al. Nonalcoholic fatty liver disease: a feature of the metabolic syndrome. Diabetes 2001;50:1844-1850. doi: 10.2337/diabetes.50.8.1844.

[56] Bugianesi E, Gastaldelli A, Vanni E, Gambino R, Cassader M, Baldi S, et al. Insulin resistance in non-diabetic patients with non-alcoholic fatty liver disease: sites and mechanisms. Diabetologia 2005;48:634-642. doi: 10. 1007/s00125-005-1682-x.

[57] Santoro N, Kursawe R, D'Adamo E, Dykas DJ, Zhang CK, Bale AE, et al. A common variant in the patatin-like phospholipase 3 gene (PNPLA3) is associated with fatty liver disease in obese children and adolescents. Hepatology 2010;52:1281-1290. doi: 10.1002/hep.23832.

[58] Hooper AJ, Adams LA, Burnett JR. Genetic determinants of hepatic steatosis in man. J Lipid Res 2011;52:593-617. doi: 10.1194/jIr.R008896.

[59] Sanyal AJ, Chalasani N, Kowdley KV, McCullough A, Diehl AM, Bass NM, et al. Pioglitazone, vitamin $\mathrm{E}$, or placebo for nonalcoholic steatohepatitis. N Engl J Med 2010;362:1675-1685. doi: 10.1056/NEJMoa0907929.

[60] Gastaldelli A, Harrison SA, Belfort-Aguilar R, Hardies LJ, Balas B, Schenker S, et al. Importance of changes in adipose tissue insulin resistance to histological response during thiazolidinedione treatment of patients with nonalcoholic steatohepatitis. Hepatology 2009;50:1087-1093. doi: 10.1002/hep.23116.

[61] Feldman A, Eder SK, Felder TK, Kedenko L, Paulweber B, Stadlmayr A, et al. Clinical and metabolic characterization of lean caucasian subjects with non-alcoholic fatty liver. Am J Gastroenterol 2017;112:102-110. doi: 10 . 1038/ajg.2016.318.

[62] Højland Ipsen D, Tveden-Nyborg P, Lykkesfeldt J. Normal weight dyslipidemia: Is it all about the liver? Obesity (Silver Spring) 2016;24:556-567. doi: 10.1002/oby. 21443.

[63] Badoud F, Perreault M, Zulyniak MA, Mutch DM. Molecular insights into the role of white adipose tissue in metabolically unhealthy normal weight and metabolically healthy obese individuals. FASEB J 2015;29:748-758. doi: 10. 1096/fj.14-263913.

[64] Fabbrini E, Magkos F, Mohammed BS, Pietka T, Abumrad NA, Patterson BW, et al. Intrahepatic fat, not visceral fat, is linked with metabolic complications of obesity. Proc Natl Acad Sci U S A 2009;106:15430-15435. doi: 10. 1073/pnas.0904944106.
[65] Kato K, Takamura T, Takeshita Y, Ryu Y, Misu H, Ota T, et al. Ectopic fat accumulation and distant organ-specific insulin resistance in Japanese people with nonalcoholic fatty liver disease. PLoS One 2014;9:e92170. doi: 10.1371 /journal.pone.0092170.

[66] Tessari P, Coracina A, Cosma A, Tiengo A. Hepatic lipid metabolism and nonalcoholic fatty liver disease. Nutr Metab Cardiovasc Dis 2009;19:291-302. doi: 10.1016/j.numecd.2008.12.015.

[67] Kim NH, Kim JH, Kim YJ, Yoo HJ, Kim HY, Seo JA, et al. Clinical and metabolic factors associated with development and regression of nonalcoholic fatty liver disease in nonobese subjects. Liver Int 2014;34:604-611. doi: 10. $1111 /$ liv. 12454 .

[68] Ampuero J, Ranchal I, Gallego-Durán R, Pareja MJ, Del Campo JA, PastorRamírez $\mathrm{H}$, et al. Oxidized low-density lipoprotein antibodies/high-density lipoprotein cholesterol ratio is linked to advanced non-alcoholic fatty liver disease lean patients. J Gastroenterol Hepatol 2016;31:1611-1618. doi: 10.1111 /jgh. 13335 .

[69] Bouloumié A, Curat CA, Sengenès C, Lolmède K, Miranville A, Busse R. Role of macrophage tissue infiltration in metabolic diseases. Curr Opin Clin Nutr Metab Care 2005;8:347-354. doi: 10.1097/01.mco.0000172571. 41149.52 .

[70] Xu H, Barnes GT, Yang Q, Tan G, Yang D, Chou CJ, et al. Chronic inflammation in fat plays a crucial role in the development of obesity-related insulin resistance. J Clin Invest 2003;112:1821-1830. doi: 10.1172/JCI19451.

[71] Kumar R, Prakash S, Chhabra S, Singla V, Madan K, Gupta SD, et al. Association of pro-inflammatory cytokines, adipokines \& oxidative stress with insulin resistance $\&$ non-alcoholic fatty liver disease. Indian J Med Res 2012;136:229-236.

[72] Motoshima H, Wu X, Sinha MK, Hardy VE, Rosato EL, Barbot DJ, et al. Differential regulation of adiponectin secretion from cultured human omental and subcutaneous adipocytes: effects of insulin and rosiglitazone. J Clin Endocrinol Metab 2002;87:5662-5667. doi: 10.1210/jc.2002-020635.

[73] Wigg AJ, Roberts-Thomson IC, Dymock RB, McCarthy PJ, Grose RH, Cummins AG. The role of small intestinal bacterial overgrowth, intestinal permeability, endotoxaemia, and tumour necrosis factor alpha in the pathogenesis of non-alcoholic steatohepatitis. Gut 2001;48:206-211. doi: 10 . 1136/gut.48.2.206.

[74] Fialho A, Fialho A, Thota P, McCullough AJ, Shen B. Small intestinal bacterial overgrowth is associated with non-alcoholic fatty liver disease. J Gastrointestin Liver Dis 2016;25:159-165. doi: 10.15403/jgld.2014.1121.252.iwg.

[75] Kapil S, Duseja A, Sharma BK, Singla B, Chakraborti A, Das A, et al. Small intestinal bacterial overgrowth and toll-like receptor signaling in patients with non-alcoholic fatty liver disease. J Gastroenterol Hepatol 2016;31: 213-221. doi: 10.1111/jgh.13058.

[76] Visser ME, Lammers NM, Nederveen AJ, van der Graaf M, Heerschap A, Ackermans MT, et al. Hepatic steatosis does not cause insulin resistance in people with familial hypobetalipoproteinaemia. Diabetologia 2011;54: 2113-2121. doi: 10.1007/s00125-011-2157-x.

[77] Freeman HJ. Hepatic manifestations of celiac disease. Clin Exp Gastroenterol 2010;3:33-39. doi: 10.2147/CEG.S7556.

[78] Kneeman JM, Misdraji J, Corey KE. Secondary causes of nonalcoholic fatty liver disease. Therap Adv Gastroenterol 2012;5:199-207. doi: 10.1177/ $1756283 \times 11430859$

[79] Akyuz U, Yesil A, Yilmaz Y. Characterization of lean patients with nonalcoholic fatty liver disease: potential role of high hemoglobin levels. Scand J Gastroenterol 2015;50:341-346. doi: 10.3109/00365521.2014.983160.

[80] Yilmaz Y, Senates E, Ayyildiz T, Colak Y, Tuncer I, Ovunc AO, et al. Characterization of nonalcoholic fatty liver disease unrelated to the metabolic syndrome. Eur J Clin Invest 2012;42:411-418. doi: 10.1111/j.1365-2362. 2011.02597.x.

[81] Zheng W, McLerran DF, Rolland B, Zhang X, Inoue M, Matsuo K, et al. Association between body-mass index and risk of death in more than 1 million Asians. N Engl J Med 2011;364:719-729. doi: 10.1056/NEJMoa1010679.

[82] Dela Cruz AC, Bugianesi E, George J, Day CP, Liaquat H, Charatcharoenwitthaya $\mathrm{P}$, et al. Characteristics and long-term prognosis of lean patients with nonalcoholic fatty liver disease. Gastroenterology 2014;146:S-909. doi: 10. 1016/S0016-5085(14)63307-2.

[83] Sung KC, Ryan MC, Wilson AM. The severity of nonalcoholic fatty liver disease is associated with increased cardiovascular risk in a large cohort of non-obese Asian subjects. Atherosclerosis 2009;203:581-586. doi: 10. 1016/j.atherosclerosis.2008.07.024.

[84] Jin YJ, Kim KM, Hwang S, Lee SG, Ha TY, Song GW, et al. Exercise and diet modification in non-obese non-alcoholic fatty liver disease: analysis of biopsies of living liver donors. J Gastroenterol Hepatol 2012;27:1341-1347. doi: $10.1111 / \mathrm{j} .1440-1746.2012 .07165 . \mathrm{x}$

[85] Bhat G, Baba CS, Pandey A, Kumari N, Choudhuri G. Insulin resistance and metabolic syndrome in nonobese Indian patients with non-alcoholic fatty liver disease. Trop Gastroenterol 2013;34:18-24. doi: 10.7869/tg.2012.86.

[86] Margariti E, Deutsch M, Manolakopoulos S, Papatheodoridis GV. Non-alcoholic fatty liver disease may develop in individuals with normal body mass index. Ann Gastroenterol 2012;25:45-51. 